\title{
Stab resistance of bulletproof vests. A conceptual model of test bench
}

\author{
Svetlana Yaneva \\ Technical University of Sofia, Faculty of Mechanical Engineering, Department of Fundamentals and Technical Means of Design, \\ Bulgaria
}

\begin{abstract}
This paper presents a conceptual model of a stand to test the physico-mechanical characteristics of materials used in the soft panels of bulletproof vests for their stab resistance to cold weapons having a sharpened blade portion firmly and rigidly attached to handle. In the process of conceptual design of the model, the requirements and norms set out in two of the leading standardization documents used to determine the stab resistance of the bulletproof vests: the standard of the US National Institute of Justice NIJ 0115.00, Stab Resistance of Personal Body Armor, and the UK Police Standard - HOSDB 2007. Part 3 Knife and Spike Resistance, have been taken into account. 3D models of the stand and its individual constructive elements were developed, on the basis of which were offered real elements and devices for its elaboration. The designed stand is technologically accessible, inexpensive and easy to manufacture and install. It can be used to pre-determine the stab resistance of different types of materials and their combinations used in the soft panels of the bulletproof vests in the process of improving their structure. Availability of such stands in the equipment of the producers laboratories involved in this type of activity would reduce costs and shorten the evaluation time of the tested materials in order to verify their compliance with standard requirements since only samples showing the highest stab resistance will have to be sent for testing in certified and accredited laboratories.
\end{abstract}

\section{Introduction}

Nowadays, the issue of the security of law enforcement, such as anti-terrorism, police and security guards, is extremely up-to-date. Of great importance for the protection of their health and life during the performance of their official duties are the personal protective equipment to which the bulletproof vests belong.

The design and protective features of modern bulletproof vests are continually being refined to meet the wide range of weapons and ammunition used. In addition to ballistic protection from a wide range of bullets and splinters, they also need to provide adequate protection against stabbing with a cool weapon, which is of great importance in close contact with an attacker. An important role in this respect is the materials that make up the soft panel of the bulletproof vest $[1,2]$. They need to be thoroughly studied, analyzed and carefully combined.

In the process of refinement of the soft panels, the various combinations of materials used to construct their structure should be subjected to a series of tests, depending on the desired level of protection, in order to establish their protective properties and suitability for use. They must guarantee high security values and full protection for all vital organs, subject to strict weight limitations for the bulletproof vest and meet the requirements of any of the applicable standards in the field [3-5].

In this report is presented a conceptual model of a stand to test the physico-mechanical characteristics of materials used in the soft armor of a bulletproof vest for their stab resistance by a cold weapon having a sharpened blade portionmour firmly and rigidly attached to handle.

\section{Basic requirements for the developed stand}

In the process of conceptual design of the model the requirements and norms set out in two of the leading standardization documents used to determine the durability of the bulletproof vests: the standard of the US National Institute of Justice - NIJ 0115.00, Stab Resistance of Personal Body Armor [3] and the UK Police Standard - HOSDB 2007. Part 3 - Knife and Spike Resistance [4], have been taken into account. The following additional requirements to which the model of test bench must respond, have been formulated:

- technologically accessible, easy to manufacture and install;

- modular construction type;

- mobile and repairable construction;

- high accuracy of tests;

Corresponding author: svetlana_ianeva@tu-sofia.bg 
- optimal price;

- the free fall of the puncture blade under the action of its own weight;

- stand height, providing the necessary energy for testing at all levels of protection;

- possibility of adjusting the angle of encounter of the test blade with the test sample against the normal at $0^{\circ}, 15^{\circ}, 30^{\circ}$ and $45^{\circ}$;

- the possibility of conducting tests according to the methodologies of the aforementioned standardization documents.

The test stand is designed to work in laboratory conditions to pre-determine the resistance to puncture of different types of materials and their combinations used in soft armor panels in the process of refinement of their structure.

The 3D models of the stand and the individual elements of its construction have been developed using SolidWorks [6].

\section{Main components and the principle of the action of the stand}

The construction of the stand is built on a modular principle and includes a basic module (Fig.1) and an additional module (Fig.2):

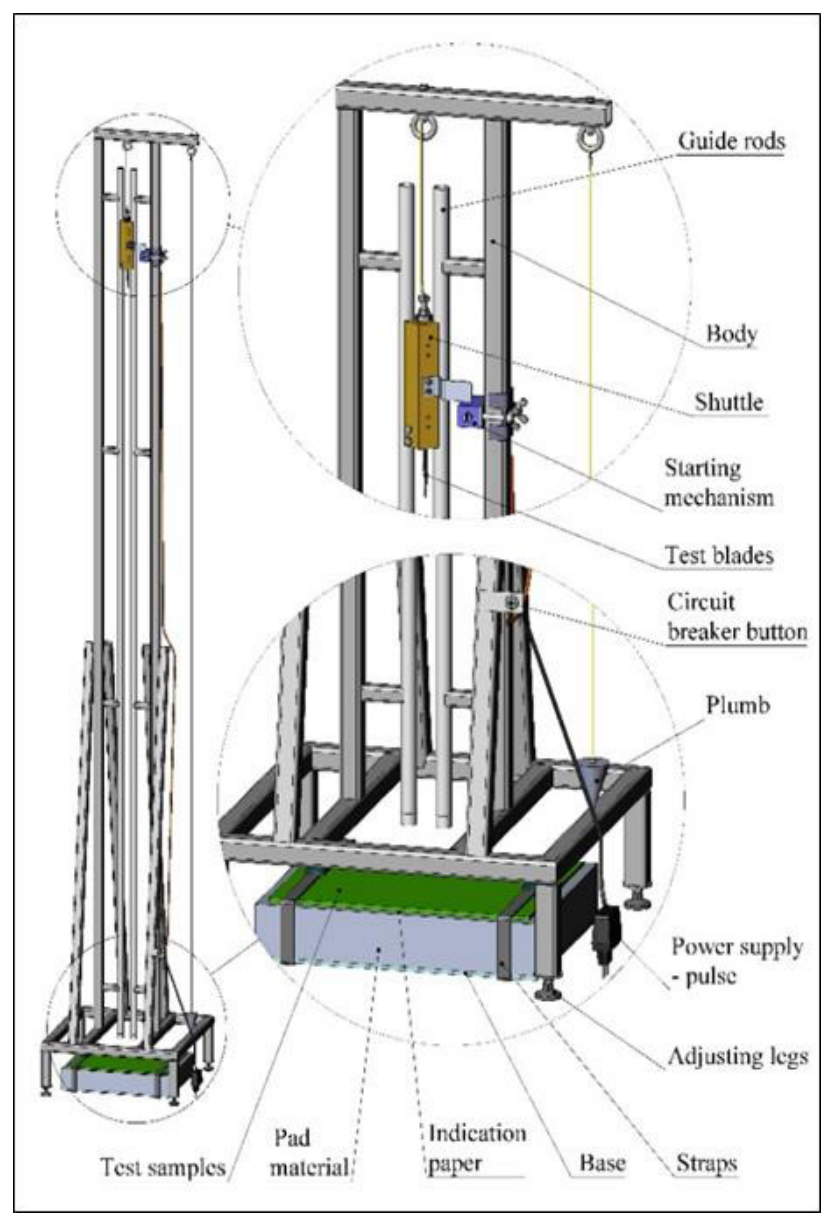

Fig. 1. Design of the stand, basic module (3D model S. Yaneva).

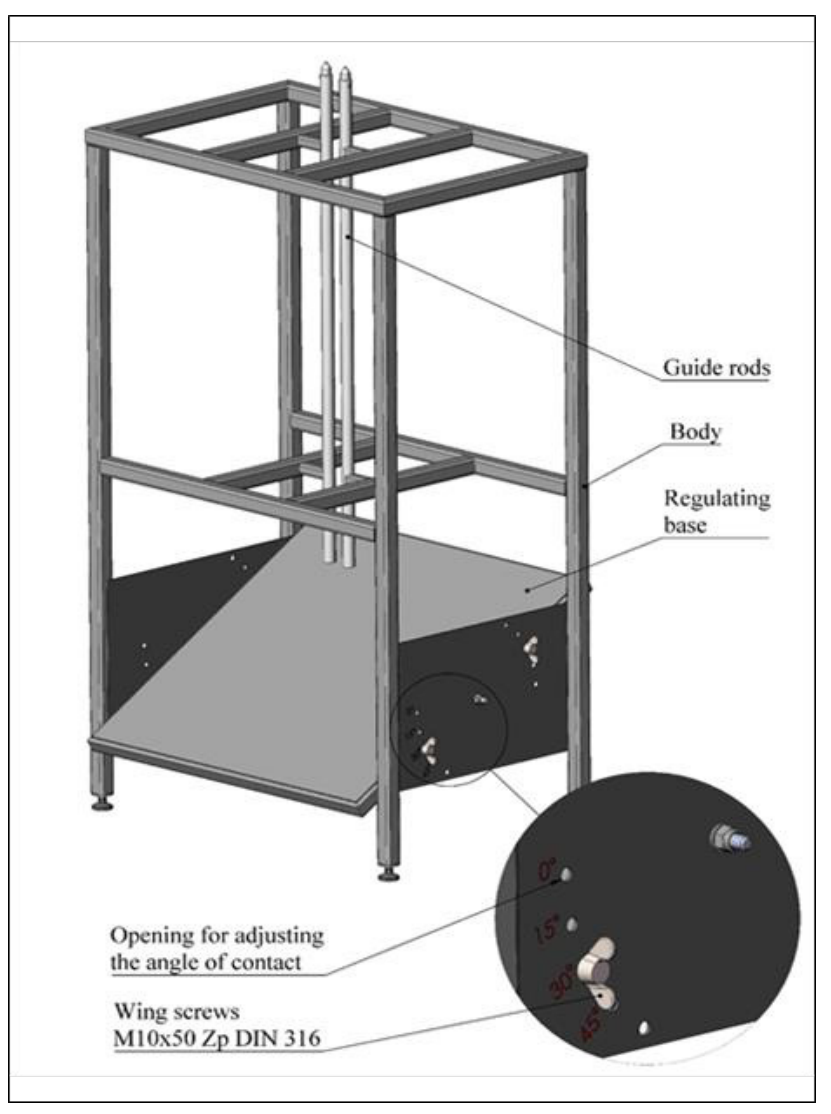

Fig. 2. Design of the stand, additional module (3D model S. Yaneva).

\subsection{Basic module}

The basic module is used to test for resistance to puncture of soft ballistic bulletproof panels for the first and second protection levels according to NIJ 0115.00, at the test blade angle with the test specimen $0^{\circ}$ relative to the normal one. It consists of:

\subsubsection{Body}

Welded construction of steel tube profiles, powder coated, to which the following components are mounted:

\subsubsection{Guide rods}

Pipe sections with circular cross section, made of stainless steel whose function is to ensure a vertical drop of the shuttle carrying the test blade in the friction stand construction tending to zero.

\subsubsection{Shuttle}

This is the device (Fig. 3) with a precise mass (1900g \pm $15 \mathrm{~g}$ ), consisting of a body (pos.1) of a specific shape made of brass alloy at the lower end, whereby by means of screws (pos.2) attach the test blade (pos.3). In the middle part of the brass body, a plate (pos.5) is fastened by means of two screws (pos.4) to fix the shuttle to the trigger mechanism. A screw (pos.6) is attached to the upper part of the body with calibrated weights (pos.7) 
serving to adjust the mass of the shuttle, which are fixed with a nut (pos.8). A textile cord is attached to the screw (pos.6) to bring the shuttle to its starting position after impact on the test specimen. The shuttle moves in the guides whose function is to ensure that the test blade (vertical) drops freely in the construction of the stand, with a friction that is tilted to zero. It falls freely at a specific height (so as to provide the required impact energy for the given level of protection) under its own weight while the test blade attached to it strikes the front of the test specimen with a certain force. The shuttle is designed such that, when the test blade is attached, it is $83 \mathrm{~mm} \pm 2 \mathrm{~mm}$ away from it. The shape of the lower surface of the falling body allows for a minimum of 30 $\mathrm{mm}$ penetration at the impact of the bulletproof vest at a $45^{\circ}$ angle from the normal.

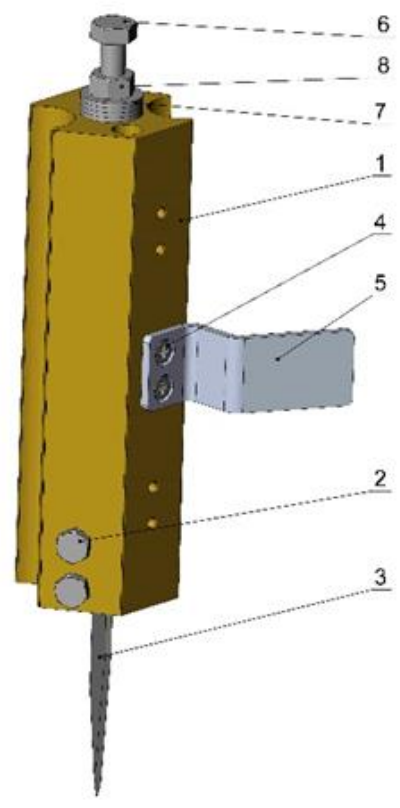

Fig. 3. Shuttle (3D model S. Yaneva).

In Fig. 4 shows the structure of the device carrying the test blade according to NIJ 0115.00, called "Drop mass". In Fig. 5 shows the device carrying the test blade, used in tests on HOSDB 2007. Part 3, called "Missile".

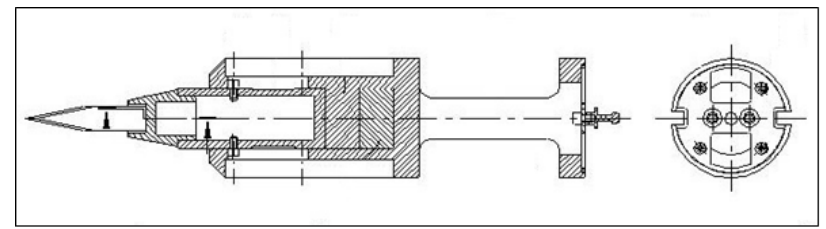

Fig. 4. Drop mass (NIJ 0115.00) [3]

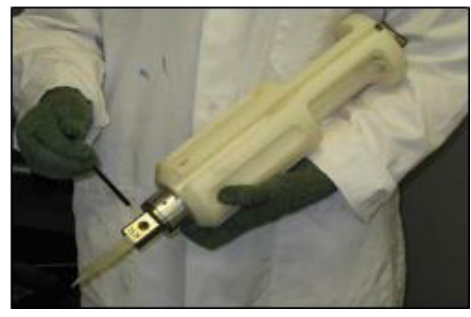

Fig. 5. Missile (HOSDB 2007. Part 3) [4].

\subsubsection{Starting mechanism (Fig. 6)}

It consists of an electromagnet pulling (real element) and a stand, which makes it possible to easily move the trigger mechanism to the required test height by means of nut screws.

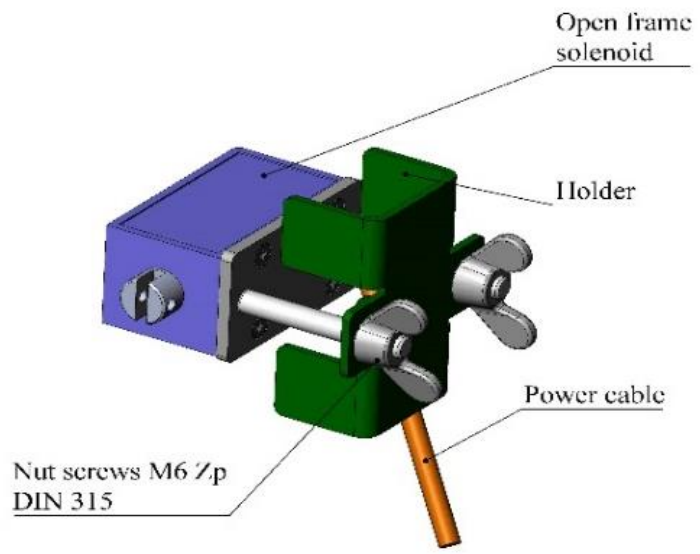

Fig. 6. Starting mechanism - open frame solenoid (3D model S. Yaneva).

\subsubsection{Circuit breaker button}

Used to set into motion the trigger mechanism by manually turning on the electric circuit. The button switch (Fig. 7) is made of a contact system, a body and a button.

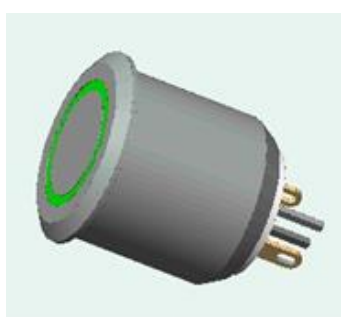

Fig. 7. Circuit breaker button (3D model S. Yaneva).

\subsubsection{Power supply - pulse}

Provides the required power to operate the trigger mechanism. A Wall Mount Power Adapter (Fig. 8) is selected, an input voltage of $90 \div 264 \mathrm{VAC}$; output voltage $24 \mathrm{VDC}$; output current $0.5 \mathrm{~A}$; maximum power $12 \mathrm{~W}$; $\mathrm{CP}>77,80 \%$; operating temperature $0^{\circ} \mathrm{C} \sim+40^{\circ}$ C; sizes $63 \times 45 \times 29 \mathrm{~mm}$.

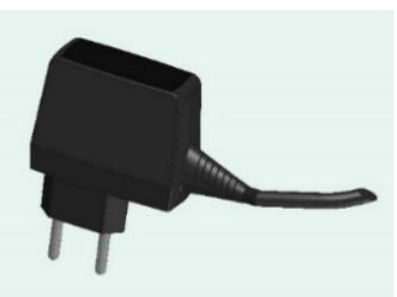

Fig. 8. Power supply - pulse (3D model S. Yaneva). 


\subsubsection{Plumb}

A massive steel body with conical shape to which a measuring rod is attached by a threaded joint. It serves to determine and ensure perpendicularity to a horizontal plane by positioning on a certain point. A basic requirement for the appliance is its mass symmetrically positioned with respect to the axis and the point of suspension of the twine.

\subsubsection{Adjusting legs}

Used to achieve perpendicularity of the stand relative to the horizontal plane on which it is placed.

\subsubsection{Base}

It is a steel massive plate with dimensions $381 \times 305 \times 5 \mathrm{~mm}$, on which are placed the substrate, the indicator paper and the test sample.

\subsection{Additional module - Optional module (Fig. 2)}

It is used to perform tests for the third level of protection according to NIJ 0115.00 , requiring greater impact energy, respectively, and higher drop height of the test blade. The auxiliary body shall be used in addition to tests at an angle of impact of $0^{\circ}$ and in tests with an angle of impact of $15^{\circ}, 30^{\circ}$ and $45^{\circ}$ relative to the normal (at all levels of protection).

It is a welded construction of powder coated steel tubing, which is mounted to the body of the main module, centered on the guides and fixed with screws.

In Fig. 9 shows the stand used under NIJ 0115.00.
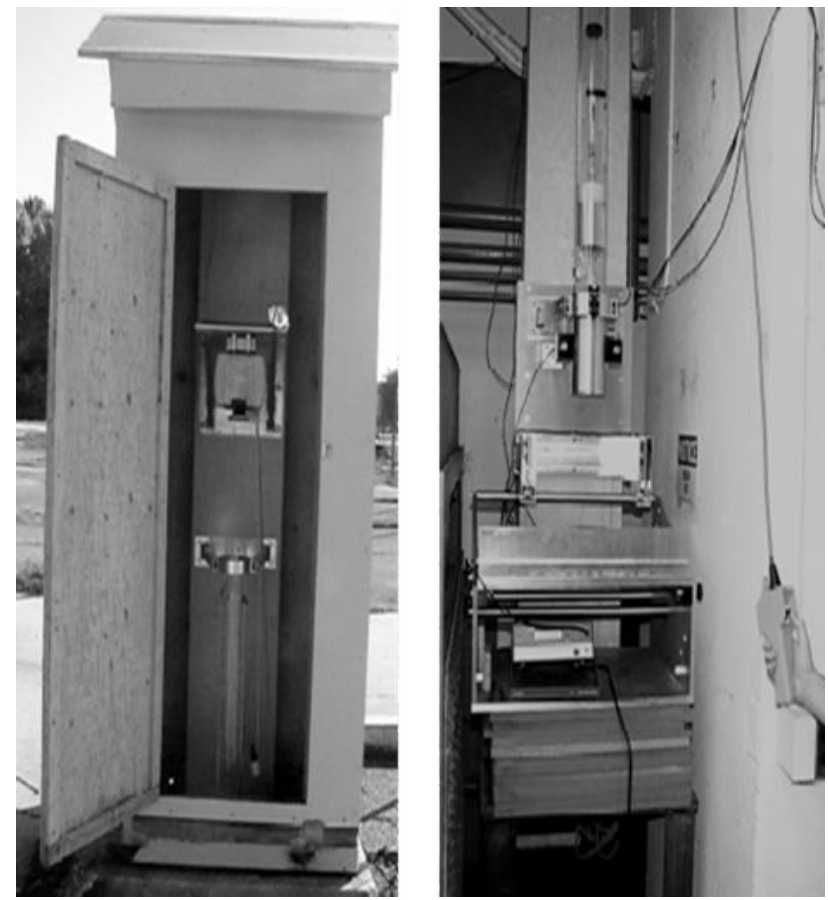

Fig. 9. Stand used in NIJ 0115.00 [3].
In Fig. 10 shows the 3D model of the entire construction of the developed stand (basic + additional module).

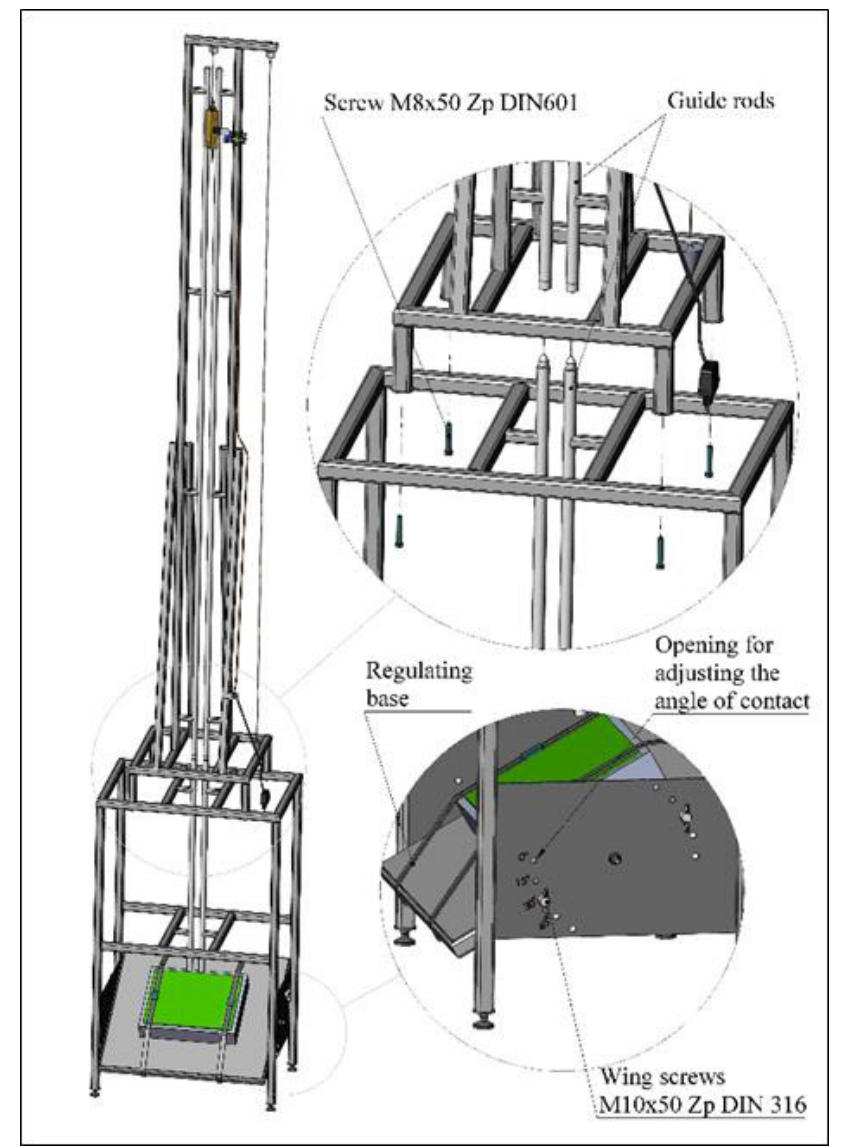

Fig. 10. Design of the whole stand, basic + additional module (3D model S. Yaneva).

\section{Conclusion and evaluation}

A conceptual model of a stand is used to determine the resistance to puncture of different types of materials and their combinations used in the soft panels of the bulletproof vests in the process of improving their structure.

The designed stand is designed for laboratory use. It is technologically accessible, easy and inexpensive for manufacturing, installation and maintenance, with a mobile and repairable modular construction.

The construction of the stand is designed to enable testing for all levels of protection regulated by the two leading standards in this area - NIJ 0115.00 and HOSDB 2007, Part 3 using their methods for testing. Due to the modular construction it is possible to use it in laboratories with insufficient height (basic module - for testing the most used first and second level of protection).

During the test, the stand has the capability to adjust the test blade angle to the test specimen relative to the normal at both $0^{\circ}$ and $45^{\circ}$ and $15^{\circ}$ and $30^{\circ}$, thus allowing for additional stress tests at these angles. 
The structure of the shuttle was changed ("Drop mass" - NIJ 0115.00; "Missile" - HOSDB 2007.Part 3, keeping the total mass required by [3].

$3 \mathrm{D}$ models of the stand and the individual elements of its construction were developed. A computer simulation of the test process was performed.

The stand can be used to pre-determine the stab resistance of different types of materials and their combinations used in the soft panels of the armor, in the process of refining their structure.

The presence of such a stand in the equipment of the relevant company laboratories involved in the improvement of the structure of the soft panels of the bulletproof vests would reduce the costs and shorten the evaluation time of the tested samples in order to check their compliance with the standards, testing only in certified and accredited laboratories will only send samples that have the highest resistance to puncture.

Acknowledgements: The author would like to thank the Research and Development Sector at the Technical University of Sofia for the financial support.

\section{References}

1. V. Nikolova, Mat. used in mak. the s. pan. of the bulletproof vest. Adv. and disadv. Conference Proceedings "Metal Science, Hydro- and Aerodynamics, National Security 2014", ISSN: 1313-8303, 405-409, Bulgaria (2015)

2. A. Bhnatagara, Material and technology. Lightweight ballistic materials, ISBN 978-5-94836163-5, Technofer, Moscow (2011)

3. NIJ 0115.00., Stab Resistance of Personal Body Armor, (NIJ, Science and Technology, Washington, DC 20531, 2000)

4. J. Croft, D. Longhurst, HOSDB Body Armor Standards for UK Police, Part3: Knife and Spike Resistance, Publication No. 39/07/C (2007)

5. M. J. Pettit, J. Croft, PSDB Stab resistance standard for body armor, Police Scientific Development Branch, Publication No. 6/99, (1999)

6. SolidWorks, Software program, published by Dassault Systèmes, (Retrieved from https://www.solidworks.com/sw/education/SDL_for m.html, 2017) 